\title{
APRECIEREA POTENTIALULUI MORFOGENETIC ȘI REGENERATIV AL GENOTIPURILOR DE TRITICALE ÎN CULTURA IN VITRO
}

\author{
Ciobanu Renata \\ Institutul de Genetică, Fiziologie şi Protecţie a Plantelor, Chișinău, Republica Moldova \\ e-mail: renata.ciobanu@igfpp.md
}

\begin{abstract}
Triticale is an important cereal crop grown throughout the world. Research showed that the regeneration of young plants from mature embryos triticale depended on genotypic characteristics. The frequency of callusogenesis varied depending on the genotype and was: 188 TR5027 - 80.19\%, Ingen 93 standard - 92.02\% and Ingen $35-98.45 \%$, and the frequency of rhizogenesis compared to embryogenesis proved to be high and constituted on average $57.35 \%$. Only in $34.53 \%$ of the morphogenic callus, the development was of the embryoid type. The average frequency of regeneration was $35.07 \%$. The dispersive analysis of the obtained results shows a significant influence of the genotype in establishing a positive callusogenetic response ( $\mathrm{P}<0.001$ ), the influence power being $76.04 \%$.
\end{abstract}

Key words: triticale, calus, calusogenesis, morphogenesis, plant regeneration.

\section{Introducere}

Direcţia principală de cercetare este dictată de necesitatea actuală şi de viitor a ţării în asigurarea securităţii alimentare [1]. Crizele climaterice, energetice şi alimentare globale şi regionale impun în faţa societăţii ştiinţifice, îndeosebi a geneticii şi fiziologiei plantelor, mari obiective de a obţine noi cunoştinţe fundamentale şi aplicate în evidenţierea, evaluarea şi dirijarea mecanismelor genetico-fiziologice a procesului de producţie şi de rezistenţă ecologică a plantelor, în cazul de faţă a triticalelor, prin îmbunătăţirea adaptabilităţii la condiţiile climatice nefavorabile: creşterea rezistenţei la stresul hidric şi termic şi obţinerea de producţii sănătoase [2].

În ultimele decenii, datorită progreselor genetice obţinute în ameliorare au fost create soiuri mult mai competitive decât genotipurile actuale de cereale păioase. Aceste soiuri sunt mai bune datorită capacităţii ridicate de producţie şi a unor însuşiri agronomice utile (rezistenţă la cădere, rezistenţă la condiţiile nefavorabile de mediu, umplerea bobului, etc.).

Din punct de vedere tehnic triticalele au o mare capacitate de a se adapta la cele mai diferite condiții climatice, ceea ce îi conferă incontestabile avantaje faţă de alte culturi mai pretențioase la factorii naturali [3].

Importanţa culturii de triticale pentru economie este explicată prin compoziţia chimică a boabelor, care le conferă însuşiri deosebite de utilizare în alimentaţie, în furajarea animalelor, precum şi în industrie.

Metodele biotehnologice, prin aplicarea tehnicilor de cultură in vitro reprezintă o cale sigură pentru obţinerea unui material biologic liber de agenţi patogeni, conservarea resurselor genetice şi calea cea mai rapidă pentru crearea şi multiplicarea genotipurilor $[4 ; 5 ; 9 ; 10 ; 12]$.

Având în vedere aceste aspecte ne-am propus stabilirea unor modalităţi de cultură care să asigure succesul regenerării in vitro a unor genotipuri valoroase din punct de vedere agronomic $[6 ; 8 ; 11]$.

\section{Materiale și metode}

Materialul biologic utilizat în acest studiu a fost reprezentat de 3 genotipuri de triticale din: Ingen 35, Ingen 93, 188TR5027. În calitate de material iniţial au servit embrionii maturi, care includ câte 120 de embrioni de la fiecare genotip. Embrionii maturi au fost aseptizaţi în soluţie de hipoclorit de $\mathrm{Na}$ în concentraţie de 7 \% timp de 30 min., apoi au urmat 3-4 spălări repetate cu apă distilată sterilă. Embrionii au fost excizaţi de pe cariopsă sub lupa binoculară, sterilizaţi suplimentar şi inoculaţi pe mediul de iniţiere a calusului. Ca substrat nutritiv de bază a servit mediul Murashige şi Skoog (1962) [7], modificat şi suplimentat cu L-asparagină-150 mg/l, mezoinozitol-100mg/l, glicină-2mg/l, zaharoză-30 mg/l, agar- 7 g/l şi reglatori de creştere: 2,4-D acid diclorofenoxiacetic, acid naphtylacetic (ANA) şi kinetină (K), BAP (6-benzilaminopurine) în diverse concentraţii şi combinaţii. Valoarea $\mathrm{pH}$-lui a fost ajustată înainte de 
autoclavare până la 5,8. Mediile nutritive s-au sterilizat prin autoclavare, în faza de vapori (10 min), apoi aerisire $(20 \mathrm{~min})$ şi sterilizare în condiţiile de presiune $\mathrm{P}=1 \mathrm{~atm}$ şi temperatura $\mathrm{T}=120^{\circ} \mathrm{C}$. Cultivarea s-a efectuat utilizând boxa cu flux laminar de aer steril. Explantele au fost cultivate la $\mathrm{T}=25-27^{0} \mathrm{C}$ la întuneric timp de două săptămâni, apoi transferate la lumină timp de 2-3 săptămâni.

Experienţele s-au efectuat după schema analizei dispersionale bifactoriale; în analiza statistică s-a utilizat pachetul de programe STATGRAPHICS Plus 2.1. Pentru analiza variaţiei şi determinarea puterii de influenţă a genotipului şi interacţiunii asupra parametrilor analizaţi s-a folosit testul ANOVA, iar pentru aprecierea diferenţelor semnificative s-a aplicat testul Student.

\section{Rezultate şi discuţii}

În scopul cercetării proceselor de calusogeneză s-au iniţiat culturi de calus din embrioni maturi la toate genotipurile studiate. Diferențierea intensă a explantelor și apariţia formării calusului pe medii de cultură au fost observate în ziua a 4-a, ceea ce este în concordanță cu datele din literatură [13; 14]. Formarea masivă de calus a fost observată la a 7-8-a zi. S-a constatat că, toate genotipurile testate au o capacitate destul de mare de inducere a calusului. Frecvența calusogenezei a variat de la 80,19 \% (188 TR5027), 92,02 \% (Ingen 93 standart) și 98,45 \% (Ingen 35) în funcție de genotip (fig. 1).

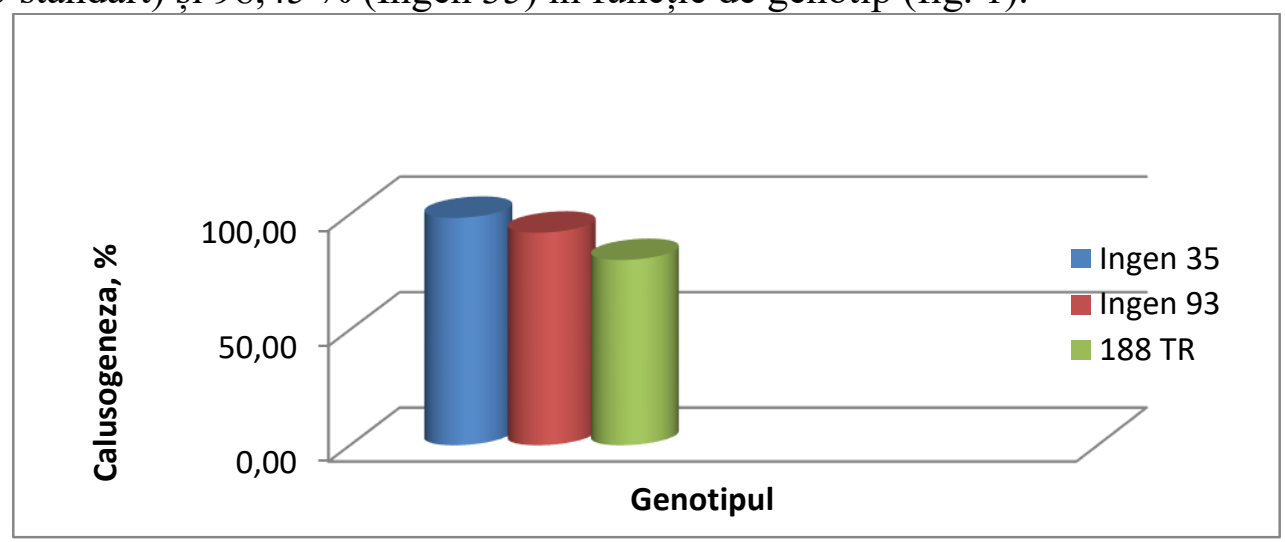

Figura 1. Frecvența calusogenezei la genotipurile de triticale.

S-a atestat formarea a 2 tipuri de calus. Primul tip de calus este embriogen - compact, structurat, de culoare gălbuie; al doilea - neembriogen, apos, de culoare alb - gălbuie.

În pofida faptului că există dovezi în literatură că, mai întâi, se formează un calus neembriogen, care fie rămâne calus primar în timpul cultivării, fie este transformat într-un tip embriogen [14], s-a observat că, calusul neembriogen, pe tot parcursul subcultivării explantelor, nu a format focare meristematice și nici nu a fost observată embriogeneza somatică.

Frecvența morfogenezei depinde de inducerea embriogenezei și rizogenezei. Genotipurile Ingen 35 și 188 TR5027 au format calus embriogen cu o rată de 34,22\% - 40,15\%. Un potențial morfogenetic scăzut atestă genotipul Ingen 93 - 29,24\% (fig.2).

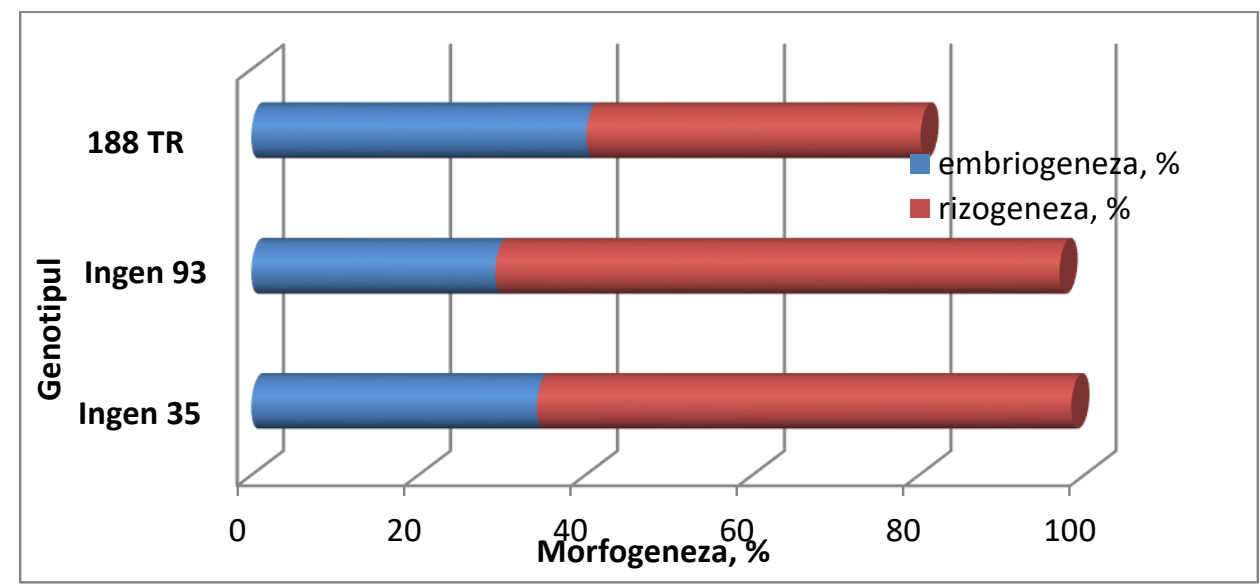

Figura 2. Frecvența morfogenezei calusului la genotipurile de triticale. 
Evident, acest lucru se datorează particularităților morfogenezei, care se desfășoară pe calea organogenezei, cu o predominanță a tipului rizogen.

Frecvența rizogenezei comparativ cu embriogeneza s-a dovedit a fi înaltă și a constituit în medie 57,35\%. Doar la 34,53\% din calusul morfogen, dezvoltarea a fost de tip embrioid. Aceasta denotă că, realizarea morfogenezei este determinată de caracteristicile genetice și fiziologice ale explantului. Embrionii somatici care s-au format în calusul morfogen, în procesul de creștere și dezvoltare, au apărut pe suprafața calusului și au format regeneranți.

Regenerarea stabilă a plantelor este o condiție pentru utilizarea practică a culturii in vitro. Frecvența regenerării în medie a constituit $35,07 \%$. Potențialul de regenerare a variat semnificativ în funcție de genotip. Dacă la genotipurile Ingen 35 (49,03\%) și Ingen 93 (40,70\%), atunci pentru genotipul 188 TR5027 a constituit doar 15,50\%, fiind o rată mică de regenerare (fig. 3).

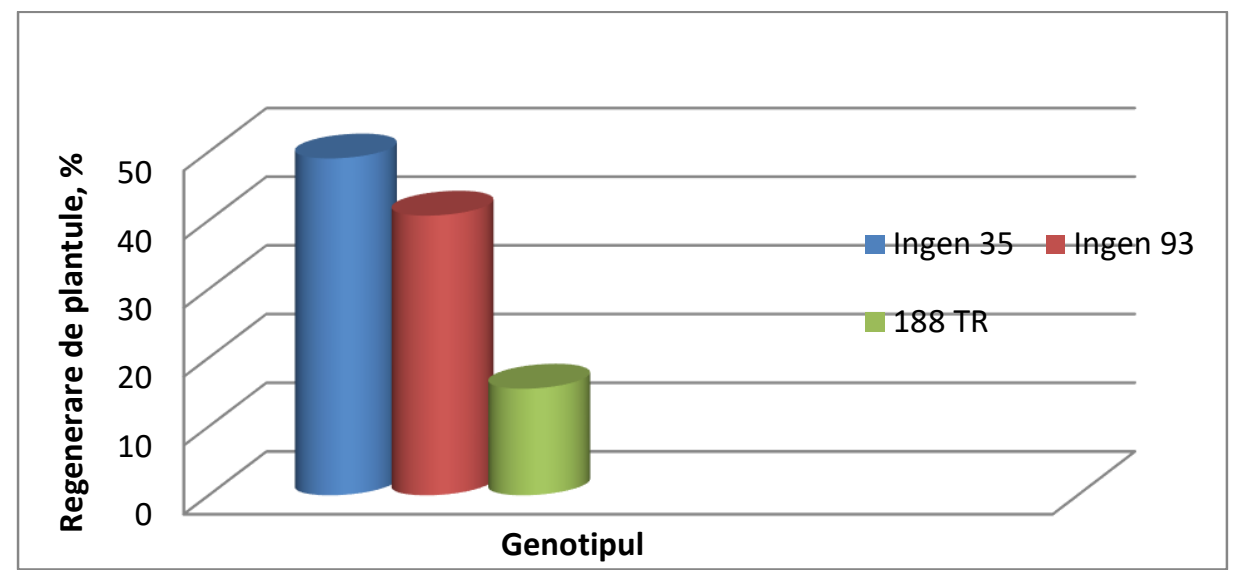

Figura 3. Frecvența regenerării de plantule.

Numărul regeneranților obținuți din calus morfogen a fost de 0,2 și 1,3 buc. respectiv. Aceasta se datorează faptului că un număr mare de calusuri morfogene s-au dezvoltat pe calea rizogenezei, ceea ce exclude posibilitatea de a obține plante.

Analiza varianței a făcut posibilă identificarea factorilor semnificativi care influențează calusogeneza, morfogeneza și regenerarea. Frecvența calusogenezei, de regulă, depinde de un număr de factori aleatori. Un factor semnificativ pentru acest indicator este genotipul. Comparând contribuția diferiților factori și interacțiunea lor între ei, trebuie remarcat faptul că genotipul joacă un rol semnificativ nu numai în procesul de calusogeneză, constituind $76,04 \%$, dar determină și capacitatea de regenerare, manifestând o putere de influenţă de $69,15 \%$ cu diferenţe semnificative pentru $\mathrm{P} \leq 0,05$.

\section{Concluzii}

1. Cercetările efectuate au demonstrat că iniţierea calusogenezei şi regenerării de plantule din embrioni maturi la triticale depinde de caracteristicile genotipice.

2.Frecvența calusogenezei a variat în dependență de genotip și a constituit: 188 TR5027 -80,19\%, Ingen 93 standart - 92,02\% și Ingen 35 - 98,45\%, iar frecvența rizogenezei comparativ cu embriogeneza s-a dovedit a fi înaltă și a constituit în medie 57,35\%. Doar la 34,53\% din calusul morfogen, dezvoltarea a fost de tip embrioid. Frecvența regenerării în medie a constituit 35,07\%.

3.Analiza dispersională a rezultatelor obţinute, denotă o influenţă semnificativă a genotipului în stabilirea unui răspuns pozitiv calusogenetic $(\mathrm{P} \leq 0,001)$, puterea de influenţă constituind $76,04 \%$.

Cercetările au fost realizate în cadrul proiectului Programului de Stat 20.80009.5107.03 "Valorificarea eficientă a resurselor genetice vegetale și biotehnologiilor avansate în scopul sporirii adaptabilitătii plantelor de cultură și schimbările climatice”, finanțat de Agenția Națională pentru Cercetare și Dezvoltare. 


\section{Bibliografie}

1.COTIANU, R.D., 2005 - Politici şi strategii globale de securitate alimentară. ASA Bucureşti: 100-115.

2.TUDOSE-SINESCU, V. Cercetări ecologice asupra culturilor de triticosecale înfiinţate pe solurile podzolice de la albota - argeş, 2010,Teză de doctorat.

3. POJMAJ, M.S., POSMAJ, R., 2006 - Breeding triticale for sprouting resistanceand baking quality. Proc. of. 6 th Intr. Sym. Stellenbosch, Sout Africa, 3-7 sept, 60.

4.MORARU, I., RĂDUCANU, F., 1990 - INCDA Fundulea, Realizări în domeniul biotehnologiei vegetale, Analele INCDA, vol. LXXV, p. 88-93 106.

5.HUSSAIN, M., KHAN, G.S., SHAHEEN, M.S., AHMAD, M. (2001). Somaclonal variation in regenerated plants of ten wheat genotypes. J. Agric. Res. 39, 1, 1-7.

6.CHEN J., YUE R., XU H., CHEN X. Study on plant regeneration of wheat mature embryos under endospermsupported culture // Agric. Sci. China. - 2006. - V. 5, № 8. - P. 572-578.

7.MURASHIGE, T., SKOOG, F. A revised medium for rapid growth and bioassay with tobacco tissue cultures // Physiol. Plant. - 1962. - V. 15. - P. 473-479.

8.КОЗЫРЕВА О.Г., ДУНАЕВА С.Е. Генетика регенерации в культуре in vitro злаков // Генетика, 1994, том 30, 10, c.1432-1440.

9.КАТАСОНОВА, А.А. Оптимизация технологии получения растений-регенерантов яровой мягкой пшеницы в каллусной культуре in vitro: Автореферат диссертации на соискание ученой степени канд. биол. наук. - Уфа: Ин-т биол. УНЦ РАН. 2007.

10.КРУГЛОВА, Н.Н., КАТАСОНОВА, А.А. Незрелый зародыш пшеницы как морфогенетический компетентный эксплант // Физиология и биохимия культ. растений. -2009. - Т. 41, № 2. - Р. 124-131.

11.ПЫКАЛО, С.В., ЗИНЧЕНКО, М.А., ВОЛОЩУК, С.И., ДУБРОВНАЯ, О.В. Морфогенез тритикале озимого в культуре апикальных меристем побегов // Сб. матер. I Междунар. научн.-практ. конф. «Биотехнология: достижения и перспективы развития», Пинск, 25-26 сентября 2014 г. - Пинск, 2014. - С. 29-34. Сатарова.

12.НИКИТИНА, Е.Д., ХЛЕБОВА, Л.П., ПРОНИНА, Р.Д. (2015). Сомаклональная изменчивость in vitro как источник создания исходного материала для селекции мягкой пшеницы. Acta Biologica Sibirica, 1 (3-4), 171-186.

13.ТАНАСИЕНКО, И.В., ЕМЕЦ, А.И., БЛЮМ, Я.Б. Оценка эффективности каллусообразования и регенерации яровых сортов ячменя, районированных на территории // Цитология и генетика, 2009. - № 4. - С. 12-19.

14.ЗАУШИНЦЕНА, А. В., БЕРЕЗИН, В. Ю. Оценка эффективности образования каллуса у тимофеевки луговой на селективных средах // Вестник Кемеровского государственного университета, 2015. - № 1 (61). T. 4. - C. 7- 10 . 